\title{
Analysis of assessment practice and subsequent performance of third year level students in natural sciences
}

\author{
K.C. Lucas \\ Department of Biochemistry, \\ Microbiology \& Biotechnology, \\ School of Molecular and Life \\ Sciences, University of Limpopo, \\ South Africa \\ kirsten.lucas@ul.ac.za
}

\author{
S.M. Dippenaar \\ Department of Biodiversity, \\ School of Molecular and Life \\ Sciences, University of Limpopo, \\ South Africa
}

\author{
P.H. Du Toit \\ Department of Humanities Edu- \\ cation, University of Pretoria, \\ South Africa
}

\begin{abstract}
Summative assessment qualifies the achievement of a student in a particular field of specialization at a given time. Questions should include a range of cognitive levels from Bloom's taxonomy and be consistent with the learning outcomes of the module in question. Furthermore, a holistic approach to assessment, such as the application of the principles of the Herrmann Whole Brain Model, needs to be used to accommodate learning style diversity. The purpose of this study was to analyse, assess and compare the summative assessment of two third year level modules in the Bachelor of Science degree programme, namely Biochemistry and Zoology as part of action research with a view to enhancing the professional development of the lecturers involved. The questions posed in summative assessments were classified in terms of Bloom's differentiation of cognitive levels and the four different learning styles determined by Herrmann. Spearman's non-parametric analysis indicated that no correlation existed in this study between cognitive level and student performance based on achievement. In addition, there was not much difference between the cognitive levels and student performance between the two disciplines. Although the students seemed to do better at application level questions, the authors need to reflect on whether the assessments were valid with respect to the learning outcomes, methods of facilitating learning, and the assessments based on cognitive levels and learning style preferences. We conclude that continuous action research must be taken to improve the formulation of learning outcomes and students' achievement of these outcomes
\end{abstract}


and quality of student learning - the main aim being the successful completion of the modules.

Keywords: assessment, whole brain learning, Bloom's taxonomy, professional development, action research

\section{Introduction}

Academic staff in universities are bestowed with the responsibility of contributing to developing the full potential of students entrusted to their care, ensuring that they are empowered to obtain the necessary knowledge, skills and competencies and to develop a positive attitude that will contribute to their success in future careers and promote lifelong learning. With universities at the top of the educational system as places to search for and disseminate knowledge (Gbadamosi and De Jager, 2009: 879), assessment forms an integral part of appraisal of students' work and performance (cf. Grant, 2008: 2; Bansilal, James and Naidoo, 2010: 155), as well as of the learning process (Burton, 2009: 6). It is the assimilation and interpretation of evidence about students' levels of skills and knowledge, in relation to predetermined standards, and should challenge students to the limits of their understanding and abilities to apply knowledge and to construct new meaning. Thus, summative assessment should discriminate between the achievements of different students at a particular time (Holtzhausen 2010, 9 and 12). The cohort of students entering universities today, compared to those in the past, has changed considerably. Universities are no longer open to a small elitist group of carefully selected students that were able to be successful within the limited 'talk and chalk' style of lecturing, but are now open to students with diverse social and schooling backgrounds (Biggs, 1999). This broad transformation of the university population is prominent in the South African context as the higher education system strives to correct the inequalities of the past, allowing studying opportunities to students from extremely diverse social and cultural backgrounds (Le Grange, 2009). These aspects, as well as the outcomes-based approach followed in education in South Africa led to the realization that provision must be made in learning and assessment opportunities for the diversity of learning preferences of students (Holtzhausen, 2010: 2). An array of learning style theories exists (Coffield, Moseley, Hal and Ecchelstone, 2004) which all perpetuate the ideas that students have different comfort zones of thinking styles. By only catering for students with a particular kind of learning style, many students are excluded from the processes of facilitating learning and assessment due to them trying to conform to a particular style, rather than focusing at the task at hand (Felder, 1996). The models provide frameworks of various thinking styles that enable 
lecturers to design methods of facilitating learning and assessments that cater to a diverse student population leading to a deeper understanding of the knowledge, attitudes and competencies required to meet the learning outcomes (Jeffrey, 2009). One such theory that the Coffield report indicates as valid, is Herrmann's (1996) Whole Brain Model (Coffield et al., 2004). According to the Whole Brain Model learning preferences are related to the distinct clusters of cognitive functions found in the four quadrants of the brain (De Boer, Steyn and Du Toit 2001, 186). The four quadrants in the Herrmann Whole Brain Model have been divided into four distinct thinking styles. The four cognitive areas of the brain stem from a left brain dominance of factual and ordered thinking to that of the right brain dominance of emotional and holistic thinking. The focus areas of the four quadrants can be clearly seen in Table 1 and are basically described as follows (Felder, 1996):

Quadrant A (left brain cerebral) which caters for logical analytical, quantitative, factual, critical thinkers; Quadrant B (left brain limbic) which caters for sequential, organized, planned, detailed and structured thinkers; Quadrant C (right brain, limbic) catering for emotional, interpersonal, sensory, kinaesthetic, symbolic thinkers; Quadrant D (right brain, cerebral) catering for visual, holistic, innovative thinkers.

By providing for, and including all different learning styles through learning and assessment opportunities, students will not only find assessment opportunities to their liking, but will also develop in areas of lesser preference and as such become 'multiple intelligent' (Du Toit, 2008).

Different criteria for accountable assessment should be kept in mind when compiling formative and summative assessments (Du Toit, 2009). Not only is it important to address multiple thinking preferences, but it is also important to assess at the required cognitive level. The core theory of cognitive learning level used for the purpose of this study was Bloom's theory on cognitive learning (Bloom, Engelhart, Hill, First and Krathwohl, 1956). The assessment strategy should be fair and valid in terms of the cognitive levels of Bloom's taxonomy specified in the learning outcomes (Holtzhausen, 2010: 11, 14, 15). Bloom's taxonomy (Bloom et al., 1956) is one of the structures used by lecturers to assess whether learning outcomes have been achieved at a cognitive level that is sufficient for a particular module (Fitzpatrick, 2008). The basis of Bloom's taxonomy is that students are required to have the competencies at a lower level in order to accomplish competencies at higher levels. Thus, a hierarchical order of competency development is acquired starting with the lowest order being knowledge, then comprehension followed by application, analysis, synthesis and lastly evaluation/creation being at the highest or sixth order. This lends 
Table 1: Whole brain assessment model (adapted from Du Toit, 2008)

\begin{tabular}{|l|l|}
\hline Left-brain Assessment & \multicolumn{1}{|c|}{ Right-brain Assessment } \\
\hline Quadrant A & Quadrant D \\
\hline Assessment focus: & Assessment focus: \\
\hline Factual & Visual \\
\hline Logical & Holistic \\
\hline Financial & Intuitive \\
\hline Analytical & Integrating \\
\hline Fact-based & Risk-taking \\
\hline Quantitative & Synthesizing \\
\hline Quadrant B & Quadrant C \\
\hline Assessment focus: & Assessment focus: \\
\hline Risk-avoiding & Feeling-based \\
\hline Procedural & Interpersonal \\
\hline Sequential & Intrapersonal \\
\hline Organized & Kinesthetic \\
\hline Planned & Emotional \\
\hline Detailed & Musical \\
\hline
\end{tabular}

itself to the assumption that in assessment, students will do better in questions aimed at the knowledge and comprehension level than they will do in questions aimed at the analysis to evaluation level. This was indeed found to be true in a study by Fitzpatrick (Fitzpatrick, 2008) using Economics students.

Bloom's taxonomy is also an important tool to use in the formulation of learning outcomes. The learning outcomes set the standards of a programme and inform students of what and how well they should master the work in a particular module (Näsström and Henriksson, 2008: 670). The learning outcomes then inform the quality of the assessment, which invariably should also contribute to the way facilitating of learning is executed - referred to in the literature as constructive alignment (Biggs, 2003). Alignment between learning 
outcomes, methods of facilitating learning and assessment opportunities is important to maintain the quality, validity and effectiveness of the applicable learning programmes (Näsström and Henriksson, 2008: 670) or module. Once well described learning outcomes specific to a module have been set, more meaningful and accountable assessment can be carried out (Towns, 2010: 91).

In order to offer an effective module, it is necessary that all lecturers review and evaluate their own modules in a holistic manner. This will include module guidelines, learning outcomes specific to the module, facilitating of learning and assessment practices (Sayigh, 2006: 164; Holtzhausen, 2010: 16). Reviewing and evaluating one's module should form part of any curriculum development process. Such curriculum development can be done through the process of action research with the purpose to go beyond the improvement of student learning and to critically investigate one's own teaching practice (cf. Burton, 2009: 7). However, investigating one's practice should not end with the identification of shortcomings, but should proceed to develop and implement remedial strategies in a repetitive fashion (cf. Rademeyer, du Plessis and Kepner, 2009: 1; Towns, 2010: 95). Identifying shortcomings and implementing remedial strategies are a deficit approach to improving one's practice - a socalled deficit approach (Du Toit, 2012). What Du Toit (2012) suggests is an asset-based approach where the focus is rather on an innovative idea, such as whole brain learning (Herrmann, 1996), which can be used to, inter alia, transform one's assessment practice. The data reported in this article serves mainly as baseline data for the action research process that we embarked on as part of our professional development.

\section{Context of study}

The context of this study is the evaluation of third year level modules presented to students in Biochemistry and Zoology. In general, students in the Faculty of Science and Agriculture had an unacceptable graduate throughput rate. Amongst others key areas identified as needing attention was the professional development of lecturers in styles of facilitating learning and methods of assessment. Therefore lecturers from various Science and Agriculture disciplines attended a professional development course on 'Innovative Facilitating of Learning and Assessment' in an attempt to improve the graduate throughput rate. Through this course, lecturers in the Faculty were introduced to, inter alia, the construct action research (McNiff, 2002). The authors identified one area of importance as being that of assessment. We analysed, evaluated and compared the summative assessment question papers and performance over two years in 
the modules mentioned above to determine whether there was a correlation between module learning outcomes, questions posed and performance of students.

\section{Purpose of the study}

The purpose of the study was to evaluate the final summative assessment questions posed in four separate examination sessions in both modules in terms of:

- cognitive levels of questions according to Bloom's taxonomy

- incorporation of the four learning style preferences posed within questions according to the whole brain theory of Ned Herrmann

- testing the assumption that students achieve a better performance in lower cognitive level questions than they would at higher levels

- testing the hypothesis that students perform better in questions that involve more than one learning style preference (see Table 1)

- comparing results between the two modules to determine whether the results are consistent across the two different disciplines

\section{Research method}

The questions in four summative question papers were analysed in terms of the cognitive level according to Bloom's taxonomy and in terms of a particular learning style preference, based on the Herrmann Whole Brain Model. Table 2 gives a broad example of some of the questions used in the study and the categories they were placed into.

The highest level of each question was determined by the wording of the question according to the illustrative verbs of Bloom's taxonomy using a list of verbs obtained from the Center for University Teaching, Learning, and Assessment (http://uwf.edu/cutla/SLO/ActionWords.pdf). In questions where the verb did not clearly describe the Bloom's level of cognitive skills, the level of the question was contextualized by analysing the expected answer according to the memoranda. This score has been presented as a percentage of the total marks as there was only one value allocated per mark allocation.

The preference of learning style into which the majority of each of the questions fell was assessed using the Herrmann Whole Brain Model of competencies 
Table 2: Examples of questions asked and allocation into Bloom's cognitive levels and Herrmann's whole brain thinking preferences

\begin{tabular}{|l|c|l|}
\hline Question & \multicolumn{1}{|c|}{ Bloom's level } & Herrmann whole brain quadrant \\
\hline $\begin{array}{l}\text { Many chemicals are used in } \\
\text { laboratories and the correct disposal } \\
\text { of them is important. Discuss the "do" } \\
\text { and "don'ts" of chemical disposal }\end{array}$ & A & \\
\hline $\begin{array}{l}\text { Using reaction equilibria explain why } \\
\mathrm{K}_{\mathrm{m}} \text { and } \mathrm{V}_{\text {max }} \text { either stay the same or } \\
\text { change in the inhibition reaction. }\end{array}$ & 2 & A; B; D \\
\hline $\begin{array}{l}\text { In order to increase the efficiency of } \\
\text { oxygen delivery from haemoglobin to } \\
\text { myoglobin, a person that moves from } \\
\text { low altitudes (high O } \mathrm{O}_{2} \text { partial } \\
\text { pressure) to high altitudes (low } \mathrm{O}_{2} \\
\text { partial pressure) will produce more } \\
2,3 \text { BPG. Explain, with the aid of a } \\
\text { graph, why this occurs. }\end{array}$ & 3 & A; D \\
\hline $\begin{array}{l}\text { Using the information below fo } \\
\text { deduce the complete primary } \\
\text { structure of the hexapeptide. Provide } \\
\text { a brief explanation as you go along, } \\
\text { e.g. Thrombin cleaves after Arg } \\
\text { thus ... }\end{array}$ & 4 & A; B \\
\hline
\end{tabular}


Table 2 (Continued)

\begin{tabular}{|c|c|c|}
\hline Question & Bloom's level & Herrmann whole brain quadrant \\
\hline $\begin{array}{l}\text { i. amino acid analysis revealed the presence } \\
\text { of Ala, Arg, Cys, His, and Phe } \\
\text { ii. Trypsin treatment yielded no fragmenta- } \\
\text { tion, however, after performic acid treat- } \\
\text { ment trypsin analysis resulted in two } \\
\text { tripeptides, one containing Cys, His } \\
\text { and Phe } \\
\text { iii. Bromelain treatment yielded a pentapeptide } \\
\text { and Ala. } \\
\text { iv. Chymotrypsin alone did not yield any } \\
\text { fragments but following performic acid } \\
\text { treatment, chymotrypsin digestion resulted } \\
\text { in a dipeptide and a tetrapeptide. }\end{array}$ & & \\
\hline $\begin{array}{l}\text { Refer to the diagram below and } \\
\text { answer the questions that follow: }\end{array}$ & 5 & $A ; D$ \\
\hline $\begin{array}{ccc} & 6 & 9 \\
& & 1 \\
& \text { Time }(\min )\end{array}$ & & \\
\hline
\end{tabular}


Table 2 (Continued)

\begin{tabular}{|l|l|l|}
\hline Question & \multicolumn{1}{|c|}{ Bloom's level } & Herrmann whole brain quadrant \\
\hline $\begin{array}{l}\text { MEC chromatograph of a protein } \\
\text { homogenate }(1 \times 10 \mathrm{~cm})\end{array}$ & & \\
i. What is the $\mathrm{V}_{\mathrm{t}}$ of the column? & & \\
ii. Which peak depicts the smallest proteins? \\
$\quad \begin{array}{l}\text { Explain your answer. } \\
\text { iii. Calculate the resolution between C and D. } \\
\text { iv. Suggest two changes you can make to the } \\
\text { chromatography in order to improve the } \\
\text { resolution between C and D. }\end{array}$
\end{tabular}


referred to in Table 1. In some questions, more than one learning style may have been allocated. Thus, the values indicated are a percentage of the marks categorized into a specific learning preference over the total mark of the paper. Addition of the percentages will thus not equate to $100 \%$. Although each lecturer initially assessed their own questions, using their experiences from offering the module, the analysis was informally moderated by the third author who was independent of the assessment process per se. To ensure a more comparable result between the two disciplines the numbers of assessments analysed were kept as similar as possible over the eight assessment opportunities within the two disciplines, although some of the numbers of assessments analysed were low in two of the assessments. The assessments used were the final summative assessment of the students in the particular discipline, as well as the re-examination of the students that were not successful in the main summative assessment. The evaluations were thus obtained from 30 randomly selected answer scripts (Assessment 1a and 2a) and all the re-assessment papers (Assessment 3a and 4a) 15 and 25 respectively for the Biochemistry examination papers. All papers in Zoology 24 (Assessment 1b); two (Assessment 2b); 29 (Assessment 3b) and seven (Assessment 4b) were analysed. In order to determine whether there was a statistically significant correlation between the level of the posed questions and the marks achieved by the students, Spearman's non-parametric correlation tests in SPSS 17.0 (Norusis 1994) were used. Additionally we compared the cognitive levels of the specified learning outcomes of each module, according to Bloom's taxonomy, with the cognitive levels of the assessment to determine if they were at the same level, hence deeming the assessments to be fair. Furthermore, the comments of the external examiners were also considered in terms of the 'standard of questions' to establish whether the assessment was valid and tested more than just mere repetition of memorized content.

\section{Results}

A range of between $33 \%$ and $49 \%$ of the questions in the Biochemistry papers corresponded to the first two lower order levels of Bloom's taxonomy, whilst the remaining percentage corresponded to levels 3 and 4 , with only a few questions, $36 \%$ in the third and fourth levels and $31 \%$ in the fifth or synthesis level from one assessment only (Table 3). Analysis of questions based on the Herrmann Whole Brain Model indicated that all questions were based on factual information as as is to be found in the A quadrant of thinking (Table 1). Where two or more quadrants were represented within one question the total marks were distributed depending on the relative weight of each thinking style's 
Table 3: Results of the percentage of marks allocated per summative assessment of the Biochemistry papers with respect to Bloom's taxonomy of cognitive learning levels and the Herrmann Whole Brain Model of thinking preferences

\begin{tabular}{|l|c|c|c|c|}
\hline & \multicolumn{4}{|c|}{$\%$ of Marks within the assessment allocated to a particular } \\
cognitive level
\end{tabular}

contribution to the answer according to the memoranda. Thus a final percentage of the mark distribution within the papers was determined as seen in Table 3. All papers had a similar learning preference distribution with a high number of questions that required only the A quadrant (48\%, 58\%, 62\% and 49\%). The B quadrant preference had a slightly lower percentage $(34 \%, 36 \%, 31 \%$ and $32 \%)$ and few questions in the D or holistic thinking style $(18 \%, 6 \%, 7 \%$ and $19 \%)$, with no question meeting the classification criteria for the $\mathrm{C}$ or emotive quadrant.

The questions posed in all of the Zoology papers were mostly at the first two cognitive levels of Bloom's taxonomy $(66 \%, 87 \%, 61 \%$ and $80 \%)$ with the highest percentage of all questions posed in all papers corresponding to the first three levels $(77 \%, 97 \%, 66 \%$ and 97\%) (Table 4). In terms of Herrmann's 
Table 4: Results of the percentage of marks allocated per summative assessment of the Zoology papers with respect to Bloom's taxonomy of cognitive learning levels and the Herrmann Whole Brain Model of thinking preferences

\begin{tabular}{|l|c|c|c|c|}
\hline & \multicolumn{5}{|c|}{$\%$ of Marks within the assessment allocated to a particular } \\
cognitive level
\end{tabular}

thinking styles all questions were represented in the A quadrant, most also included the B quadrant sequential and orderly thinking style $(66 \%, 97 \%, 93 \%$ and $97 \%)$, with fewer $(45 \%, 65 \%, 40 \%$ and $56 \%)$ in the D quadrant, whilst very few $(5 \%, 0 \%, 2 \%$ and $0 \%)$ accommodated the learning style of the $\mathrm{C}$ quadrant (Table 4).

It should be noted that a lecturer's assessment practice should be viewed in a holistic fashion as it is multidimensional. This would mean that the array of assessment opportunities should be kept in mind - making provision for all learning styles within the scope of the variation of assessments, being it written assessment, practical assessment or oral assessment. One could accept that the $\mathrm{C}$ quadrant will come more into play during oral assessment, for example. 
Table 5: Spearman's r correlation values of percentage obtained versus Bloom's taxonomy level for all papers

\begin{tabular}{|l|c|}
\hline Paper & $\begin{array}{c}\text { Bloom's Taxonomy Level Spearman's r } \\
\text { value }\end{array}$ \\
\hline BIOC 1a & -0.236 \\
\hline BIOC 2a & 0.032 \\
\hline BIOC 3a & 0.139 \\
\hline BIOC 4a & -0.042 \\
\hline ZOOL 1b & -0.129 \\
\hline ZOOL 2b & -0.104 \\
\hline ZOOL 3b & -0.173 \\
\hline ZOOL 4b & -0.176 \\
\hline Combined BIOC and ZOOL papers & -0.082 \\
\hline
\end{tabular}

The Spearman's non-parametric analysis indicated that no correlation was found between the percentage mark achieved by the student group and the level of Bloom's taxonomy of the specific question in any of the papers, as well as in a combined analysis of all papers (Table 5). The mean percentages obtained by the study population per cognitive level did not decrease with higher levels and no pattern was observed (Table 6). As mentioned earlier, no correlation was found between the percentage obtained and cognitive levels of a combination of all Biochemistry questions, Zoology questions and all questions $(\mathrm{r}=-0.236$, $-0.124,-0.082$ respectively). The analysis in terms of the whole brain principles indicated that students received similar mean percentages in questions accommodating all quadrants (Table 6).

\section{Discussion}

Seventy-seven percent of the questions asked in the eight summative assessments analysed were within the lower three levels of Bloom's taxonomy. Since the analysis of the questions was not done in a blind study, but analysed by the authors themselves, some objectivity may have been lost based on the verb used in a question and the expected answer. Although discussions did take place amongst the authors regarding the level of a question when in doubt, we did feel 
Table 6: Mean values and Spearman's $r$ values of student's \% obtained versus Bloom's taxonomy level and whole brain quadrants for a combination of all BIOC questions, a combination of all ZOOL questions, and a combination of all questions

\begin{tabular}{|l|c|c|c|c|c|c|c|}
\hline \multicolumn{4}{|c|}{ Blooms Taxonomy level } & \multicolumn{4}{c|}{ Whole brain quadrant } \\
\hline & $\begin{array}{c}\text { BIOC Mean\% } \\
\text { (Std dev) }\end{array}$ & $\begin{array}{c}\text { ZOOL Mean\% } \\
\text { (Std dev) }\end{array}$ & $\begin{array}{c}\text { BIOC and } \\
\text { ZOOL Mean\% } \\
\text { (Std dev) }\end{array}$ & $\begin{array}{c}\text { BIOC Mean\% } \\
\text { (Std dev) }\end{array}$ & $\begin{array}{c}\text { ZOOL Mean\% } \\
\text { (Std dev) }\end{array}$ & $\begin{array}{c}\text { BOOC and } \\
\text { (Std dev) }\end{array}$ \\
\hline 1 & $45(43)$ & $59(42)$ & $50(42)$ & A & $37(40)$ & $55(44)$ & $41(42)$ \\
\hline 2 & $38(35)$ & $45(41)$ & $41(38)$ & B & $47(41)$ & $50(41)$ & $47(41)$ \\
\hline 3 & $46(41)$ & $61(45)$ & $49(42)$ & $C$ & & $44(40)$ & $44(40)$ \\
\hline 4 & $31(36)$ & $46(35)$ & $35(37)$ & $D$ & $37(37)$ & $57(41)$ & $47(40)$ \\
\hline 5 & $43(31)$ & $28(19)$ & $40(30)$ & & & & \\
\hline 6 & -0.057 & -0.124 & -0.082 & & 0.033 & 0.005 & 0.049 \\
\hline $\begin{array}{l}\text { Spearman's r } \\
\text { value }\end{array}$ & & $40(37)$ & $40(37)$ & & & & \\
\hline
\end{tabular}


that a totally independent assessor, especially an assessor with no background regarding whole brain assessment, for example, may not have been in a position to evaluate the level of questions, which by using different examples in the summative assessment, had been practised within a tutorial situation and which were not. This process fits in well with the notion of self-assessment as part of professional development and taking responsibility for one's own practice. In most instances questions were assessed using verbs described by various authors as aligned with various levels of Bloom's taxonomy (Towns, 2010: 93). This could have led to some inconsistencies as questions using Bloom's taxonomy key words may not necessarily be in a particular required level (Rust, 2002: 1) and careful analysis of each question was required to ensure that questions were placed at the correct level.

The results of the categorization of the questions into learning style preferences indicated that the majority of the questions fell into the left hemisphere of the brain (Tables 3 and 4), whilst a few were categorized into the right hemisphere of the brain, with very little categorized in the emotional, expressive and kinesthetic quadrant. This indicated that our assessments are focused on a particular group of student, those with learning preferences in the A and B quadrants. The similar percentages obtained for student achievement in questions accommodating different brain quadrants (Table 6) are encouraging. It seems that students with various learning preferences are able to stretch out of their comfort zones and answer a variety of questions. However, without profiling the study population we are unable to give factual information on this. Interestingly, groups of people with similar learning styles have been allocated to typical careers (Herrmann, 1996), with scientists being linked mainly to quadrant A. The results of the study do, however, lead us to reflect that we are not providing assessments that allow all students in the study group the comfort of attending to questions within their own learning preference and that we are focusing on learning preferences similar to our own. One should be constantly aware of the diversity of thinking (learning) style preferences of students (De Boer et al., 2001: 193), and the implementation of various assessment strategies is necessary to accommodate learner (student in our context) diversity (Gopal and Stears, 2007: 17). Assessment flexibility is also very important (Allsopp, 2002) and, by providing a variety of different assessment mechanisms during the course of the module, will assist with learning style diversity.

The correlation results of this study did not indicate a negative correlation between Bloom's taxonomy level and percentages obtained as we expected based on our assumption that students should do better in pure knowledge, 
cognitive level 1, questions than they would at the higher orders. Knowledge and understanding of concepts within the study material should be the foundation for all higher levels of Bloom's taxonomy. Although concerning, this may be indicative of, amongst others, the methods of facilitating learning used, emphasis being placed on application and analysis of information during practical and tutorial sessions, or due to our initial question analysis not being as objective as it should have been. Analyses of both the Biochemistry and Zoology papers indicated that level 3 (application) had the highest scores.

Deacon, Osman and Buchler (2009: 1078) highlight a few studies on students' attitudes of what they need to know or do to 'get by'. Biggs (1999: 57-58) uses clear examples of the attitudes of two different students within a course to highlight differences of learning styles. Burton $(2009$ : 4, 9) emphasizes that in a professional development course with school teachers as learners, many admitted to wanting to know what to do to 'pass' the course, asking for the scope of tests. O'Grady (2004) concludes that, traditionally, assessment is used as a carrot to force student learning, and with traditional methods of facilitating learning, has led to superficial learning without understanding. A study by Jeffrey (2009: 195) separates students into three categories: surface learners, deep learners and those driven by competitiveness. Biggs' theory on constructive alignment emphasizes that the entire curriculum from learning outcomes, to methods of facilitating learning and assessment must align with each other (Biggs and Tang, 2007). Burton (2009: 9, 11) further highlights the important role of assessment in outcomes-based education and the need for assessment to play a meaningful role in the learning process rather than as the end result. The challenge for us, as module facilitators, would be to establish methods of facilitating learning that will require students to move towards a deeper level of learning and thus to acquire the knowledge, skills, competencies and attitudes that will enable them to perform better at all levels assessed. Students need to be stimulated early in their studies regarding the fact that gaining access to information and using it in a variety of manners will enhance their learning experience in all facets of life.

An area necessary for constructive alignment of the curriculum is the analysis of the modular learning outcomes. A reflection of the module learning outcomes for the two disciplines presented in this study, indicated that most of the learning outcomes posed were at the lower two levels of Bloom's taxonomy. The taxonomy levels were often not aligned to the same cognitive levels between that of the learning outcomes and that of the assessment paper. This is a criterion that is imperative to ensure the validity and fairness of assessment 
(Rust, 2002: 1; Näsström and Henriksson, 2008: 670; Towns, 2010: 92). The non-alignment of learning outcomes and assessment criteria is probably a large contributing factor to the poor performance of the students. It is thus important that we revise the stated learning outcomes to ensure that they are at cognitive levels relevant to the modules and thereafter, ensure that our assessments in general and assessment criteria in particular, correspond with them. Additionally, when determining the cognitive levels of the learning outcomes we will have to ensure that we take cognisance of the assessment policy pertaining to our disciplines. In addition to being informed in terms of assessment policies, we came to realize that through executing action research one becomes scholarly in one's thinking about assessment. Therefore, as a scholar one can contribute to informing policy and contributing to policy making. The current assessment policy states that 'at third year level $40 \%$ of outcomes are based on knowledge, comprehension and application and $60 \%$ on analysis, evaluation and synthesis'. From the analyses of the question papers, it is clear that the learning outcomes for each module have to be revised. Furthermore, attention should be paid to the learning outcomes when setting a question paper in order to ensure that questions are at the stated levels of the outcomes. Another resource used to ascertain whether the papers given to the Biochemistry and Zoology students were of a standard deemed appropriate for the exit level students on a national basis, the comments of the external examiners were reviewed. The external examiner reports did not indicate that the papers were of a poor quality, nor that the cognitive levels of the questions asked were too low. Comments made regarding the quality of the answers did indicate, however, that in general the students answered the questions poorly. This was in agreement to the scores initially given by us to the students. Again, this has led us to reflect on the holistic constructive alignment of the module.

There has been a universal trend to increase access to higher education (Jeffrey, 2009: 1076) and students entering have diverse social and academic backgrounds (Beylefeld, Hugo and Geyer, 2008: 948). Furthermore, high intake numbers of students and the escalating costs incurred by resources (Gbadamosi and De Jager, 2009) have added to the problems. This has required lecturers to find alternative ways to ensure that resources are effectively and efficiently used, and that study materials are easily accessible by students. Due to the increase in the use of information technologies in today's age, the use of a university IT platform to link students to information regarding the study materials has become possible at a fraction of the cost. The software programs have also enabled lecturers to develop formative assessments on these platforms that allow students the opportunity of assessing themselves to determine 
progression. With the use of innovative, colourful, animated information on the university learning platforms, we should not only be able to enhance the cognitive level of the student's competencies, but also reach a larger audience in terms of learning style preference.

\section{Conclusion}

Due to the low performance of students in the two modules studied, we as the course lecturers need to continue with our action research process to improve the knowledge, skills, attitudes and competencies of our students. Learning outcomes, methods of facilitating learning and assessment must be carefully aligned throughout all modules ensuring that they focus correctly at applicable cognitive levels, and that they incorporate many different learning styles to reach the student population in total. Reviewing current assessment practices and understanding how assessment could be improved, (Grant, 2008) is inseparable from the need to develop a more informed understanding of learning which accompanies a well-designed curriculum (Sayigh, 2006). Therefore, there is an additional need to develop and qualify assessors to deal with the challenges of curriculum design and implementation. The undertaking of this project within the university, led to many shortcomings of expertise being identified by lecturing staff. Workshops on learning outcome and assessment development, methods of facilitating learning and instructional leadership have been attended in order to increase the professional development within the university. The challenge remains for us, as lecturers, to reflect on our practices, to continually safeguard the quality of our respective modules, and to enhance the students' experience in order to ensure student success of the module, and ultimately improve graduate throughput.

\section{Funding}

This work was supported by the Improved Graduate Throughput Grant from the Department of Higher Education and Training.

\section{Notes on Contributors}

KC Lucas has lectured Biochemistry at the University of Limpopo for the last 22 years. She has lectured all levels of Biochemistry students which includes the Biochemistry third year course and presently resides in the Quality Assurance 0ffice. Her interests are curriculum design and alignment, scholarship of teaching and learning and protein biochemistry. 
SM Dippenaar has been lecturing Zoology at the University of Limpopo for the last 20 years. She has lectured all levels of Zoology students which includes the Zoology third year course since 2007. Her interests lie in Copepod Research, professional development and in teaching and learning.

PJ Du Toit has been a scholar of teaching and learning in higher education for more than 20 years and specialises in Higher Education at the University of Pretoria. His interests lie in higher education, educational leadership, curriculum design, and active learning, scholarship of teaching and learning, qualitative research, professional development, transformative learning, learning and the brain, adult and continuing education, teacher's practices, and holistic education.

\section{References}

Allsopp, L. 2002. Flexibility in assessment - an evaluation of student performance. Available at: http://proceedings.informingscience.org/IS2002Proceedings/pape rs/Allso068Flexi.pdf (accessed on 15 March 2010).

Bansilal, S., A. James and M. Naidoo. 2010. Whose voice matters? Learners. South African Journal of Education, 30 (1): 153-165.

Beylefeld, A.A., A.P, Hugo and H.J. Geyer. 2008. More learning and less teaching? Students' perceptions of a histology podcast. South African Journal of Higher Education, 22 (5): 948-956.

Biggs, J. 1999. What the student does: teaching for enhanced learning. Higher Education Research and Development, 18 (1): 57-75.

Biggs, J. 2003. Aligning teaching and assessing to course objectives. Teaching and learning in higher education: New trends and innovations. Presented at University of Aveiro, 13-17 April 2003.

Biggs, J. and C. Tang. 2007. Teaching for quality learning at university. Mainhead: Open University Press/McGraw Hill.

Bloom, B.S., M.D. Engelhart, W.H. Hill, E.J. First and D.R. Krathwohl. 1956. Taxonomy of educational objectives: cognitive domain. New York: Longman.

Burton, N. 2009. "I have a cunning plan, my Lord": application of an assessment strategy to improve student learning. African Journal of Research in MST Education, 13 (2): 3-14.

Coffield, F., D. Moseley, E. Hal and K. Ecchelstone. 2004. Learning styles and pedagogy in post-16 learning: a systematic and critical review. London: Learning and Skills Research Centre. 
De Boer, A.-L., T. Steyn and P.H. Du Toit. 2001. A whole brain approach to teaching and learning in higher education. South African Journal of Higher Education, 15 (3): 185-193.

Deacon, R., R. Osman and M. Buchler. 2009. Education scholarship in higher education in South Africa, 1995-2006. South African Journal of Higher Education, 23 (6): 1072-1085.

Du Toit, P.H. 2008. Learning style flexible assessment. In Outcomes-based assessment, edited by J.G. Maree and W.J. Fraser. Sandown: Heinemann.

Du Toit, P.H. 2009. Reader for postgraduate studies in professional development and facilitating learning. Faculty of Education, University of Pretoria.

Du Toit, P.H. 2012. Using action research as process for sustaining knowledge production: a case study of a higher education qualification for academics. South African Journal of Higher Education, 26 (6): 1216-1233.

Felder, R.M. 1996. Matters of style. ASEE Prism, 6 (4): 18-23.

Fitzpatrick, L. 2008. Assessing globally themed learning objectives using objective examination results. Journal of Economics and Economic Education Research. Available at: http://findarticles.com/p/articles/mi_qa5529/is_3_9/ai_n32103642/ (accessed on 15 March 2010).

Gbadamosi, G. and J. De Jager. 2009. 'What you see is what you get': service quality, students' perceptions and satisfaction at South African universities. South African Journal of Higher Education, 23 (5): 877-893.

Gopal, N. and M. Stears. 2007. An alternative approach to assessing science competencies. African Journal of Research in SMT Education, 11 (2): $15-24$.

Grant, R. 2008. A phenomenological case study of a lecturer's understanding of himself as an assessor. Indo-Pacific Journal of Phenomenology, 8 (Special Edition): 1-10.

Herrmann, N. 1996. The whole brain business book. New York: McGraw Hill. Holtzhausen, N. 2010. An overview of learning style flexibility and whole brain learning in assessment practice: an outcomes based approach. Journal of Public Administration, 45 (1): 2-16.

Jeffrey, L.M. 2009. Learning orientations. Diversity in Higher Education, 19 (2): 195-208.

Le Grange, L. 2009. A survey of educational research in the second decade of South Africa's democracy: a focus on higher education. South African Journal of Higher Education, 23 (6): 1115-1125.

McNiff, J. 2002. Action research for professional development: concise advice for new action researchers, 3rd ed. Available at: http://www.jeanmcniff.com/ booklet1.html\#12 (accessed on 28 March 2010). 
Näsström, G. and W. Henriksson. 2008. Alignment of standards and assessment: a theoretical and empirical study of methods for alignment. Electronic Journal of Research in Educational Psychology, 6 (3): 667-690.

Norusis, M.J. 1994. SPSS statistical procedures companion. Available at: http:// www.spss.com/worldwide (accessed on 1 June 2010).

O'Grady, G. 2004. Holistic assessment and problem based learning. Fifth AsiaPacific Conference on PBL. Available at: www.myrp.sg/ced/research/papers/ holistic_assessment_and_pbl.pdf (accessed on 16 March 2010).

Rademeyer, A., Y. du Plessis and C.H. Kepner. 2009. Human performance variation analysis: a process for human performance problem solving. South African Journal of Human Resource Management, 7 (1): 1-9.

Rust, C. 2002. Purposes and principles of assessment. Available at: www. brookes.ac.uk/services/ocsd/ (accessed on 16 March 2010).

Sayigh, E.A. 2006. Refining lecturers' assessment practices through formal professional development at Rhodes University. South African Journal of Higher Education, 20 (1): 161-173.

Towns, M.H. 2010. Developing learning objectives and assessment plans at a variety of institutions: examples and case studies. Journal of Chemical Education, 87 (1): 91-96. 